\title{
3-Dimensional
}

\section{Surface Magnetic Susceptibility Distributions with Depth to Investigate Anthropogenic Pollutants Boundary in Abuja Metropolis}

\author{
Solomon Sunday Jatto ${ }^{1}$, Peter Ojo Sule ${ }^{2}$, Lawal Aminu Ahmed ${ }^{2}$ \\ ${ }^{1}$ National Space Research and Development Agency, Space Environment Research Laboratory; \\ Abuja, Nigeria; e-mail: jattosolomon@gmail.com \\ ${ }^{2}$ Ahmadu Bello University, Department of Physics; Zaria, Nigeria
}

(C) 2016 Authors. This is an open access publication, which can be used, distributed and reproduced in any medium according to the Creative Commons CC-BY 4.0 License requiring that the original work has been properly cited.

Received: 2016-07-05; accepted: 2016-12-16

\begin{abstract}
Changes in the magnetic susceptibility of topsoil, especially in urban areas, are greatly affected by the deposition of anthropogenic metallic dust arising from industrial activities, the burning of fossil fuels, car wear, and tyre abrasion. In this study, magnetic susceptibility measurements were carried out in vertical soil profiles of $30.0 \mathrm{~cm}$ depth from the surface at $10.0 \mathrm{~cm}$ intervals in about 431 locations within the Abuja metropolis with a view to investigate the penetration ability of magnetic pollutants in the ground. From the obtained data, 3-D surface contour maps were plotted for different depths. The results show a magnetic susceptibility decrease from the surface down the ground to the depth of $30.0 \mathrm{~cm}$; most of the recorded susceptibilities were of an anthropogenic origin rather than pedogenic activities. This indicates that the anthropogenic dust depositions are mostly a surface phenomenon and may therefore not pose a risk to groundwater aquifers and near surface wells.
\end{abstract}

Keywords: vertical distribution, soil pollution, magnetic susceptibility, anthropogenic pollutants, Abuja

\section{INTRODUCTION}

One of the main causes of environmental challenges in most urban areas is that of metallic pollutants usually associated with magnetic particles. This is because these pollutants tend to affect every part of the environment, from the atmosphere, hydrosphere and lithosphere to the biosphere. Also of great importance is the fact that they can accumulate for a long time in any of their host environments.

The ability of these magnetic particles to spread over the soil surface is controlled by a number of factors like wind speed and direction, rain, flowing water etc. However, not much work has being carried out on the mechanism responsible for the vertical penetration of these magnetic particles into the soil layers This will be of considerable importance as they serve as contaminants in the environment, especially groundwater aquifers. In this study we tend to understand the distributions of these anthropogenic pollutants from the surface to a depth of about $30.0 \mathrm{~cm}$. This will make it possible to determine the penetration mechanism of magnetic particles.

Magnetic susceptibility variations are caused by differences in geology (lithogenic/geogenic), soil forming processes (pedogenesis) and the anthropogenic input of magnetic material (Thompson \& Oldfield 1986, Dearing 1999).

Investigation of pollutants of anthropogenic /industry origin have been successfully mapped out using magnetic susceptibility. This is because of the existing relationship between magnetic susceptibility 
and the concentration of heavy metals (Hunt et al. 1984, Georgeaud et al. 1997, Petrovský et al. 1999, Knab et al. 2001, Spiteri et al. 2005, Chaparro et al. 2006, Zhang et al. 2006, Kim et al. 2007).

\section{THE STUDY AREA}

Abuja is located in north central Nigeria and has an estimated population of about 3.1 million. It is a well-planned city and the capital of Nigeria. Phase 1 (the highly-developed area) of Abuja was considered in this work; this includes the districts of Wuse, Garki, Central Area, Maitama and Asokoro (Fig. 1).

Abuja is underlain by high grade metamorphic and igneous rocks of the Precambrian age trending NN-E-SS-W. These rocks are represented by gneiss, migmatites, granites and a schist belt (Kogbe 1976). The residual soils of Abuja can be divided into two major groups; the residual soil which is lateritic and a product of the intense weathering of the parent rocks and the transported soil formed by the physical movements of the soil particles. The residual soils are formed in most parts of the area except along river valleys and at the foot and summit of slopes (Malomo et al. 1983).

Generally, the study area has less industrial activities, beside major construction works going on around the city. However, the large influx of vehicles into the city remains a major source of environmental pollution. As most of the vehicles release particle matter directly into the atmosphere, these finally settle on the ground, mostly around roadside corridors and commercial places.

\section{DATA AND METHODOLOGY}

Magnetic susceptibility field measurements were taken from 471 soil profiles at different sites within the city (Fig. 1). The coordinates of the sampling sites were recorded and used with a Matlab program to indicate the point on the surface map of Abuja. A total of 389 sampling sites fall within the boundary of the city. The measurements of soil magnetic susceptibility in soil profile were performed with Bartington magnetic susceptibility metre with the D-loop sensor. Before the measurement, $30.0 \mathrm{~cm}$ deep drilling was made using a metallic pipe with a diameter of $2.20 \mathrm{~cm}$.
The measurements were carried out at the surface after clearing slightly the top surface soil, then at intervals of $10.0 \mathrm{~cm}, 20.0 \mathrm{~cm}$ and $30.0 \mathrm{~cm}$ respectively. Measurement of soil magnetic susceptibility was performed twice in order to reduce the possibility of errors due to the influence of temperature changes on the inductivity of the metre sensor. For further analyses, the average from these two measurements was used. In addition, geological mapping was conducted within the study area and magnetic susceptibility measurements were also carried out on the collected rock samples.

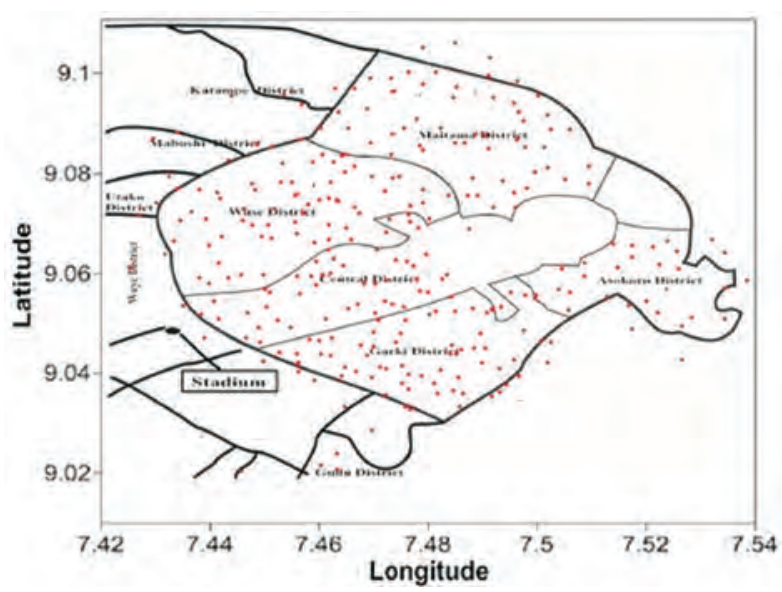

Fig. 1. Map of Abuja with the location of 471 sampling sites

\section{3-D MAGNETIC SUSCEPTIBILITY DATA INTERPRETATION}

The geologic mapping of rocks samples within the area indicates that biotite and migmatite gneiss are the predominant rocks found within the study area (Fig. 2). The spatial magnetic susceptibility distribution of these rocks shows that it varies between $(65.0-140.0) \times 10^{-5}$ with an average of $112.5 \times 10^{-5}$. The magnetic susceptibility distribution of the rocks in Abuja is shown in Figure 3.

From the weathering of basement rocks, studies have shown that magnetic minerals occur as trace minerals; thus, rock magnetic susceptibility studies utilized the magnetic contributions of these magnetic minerals within the rock.

The mean value of $112.0 \times 10^{-5}$ indicates that the magnetic susceptibility of the rocks is controlled by paramagnetic minerals. 


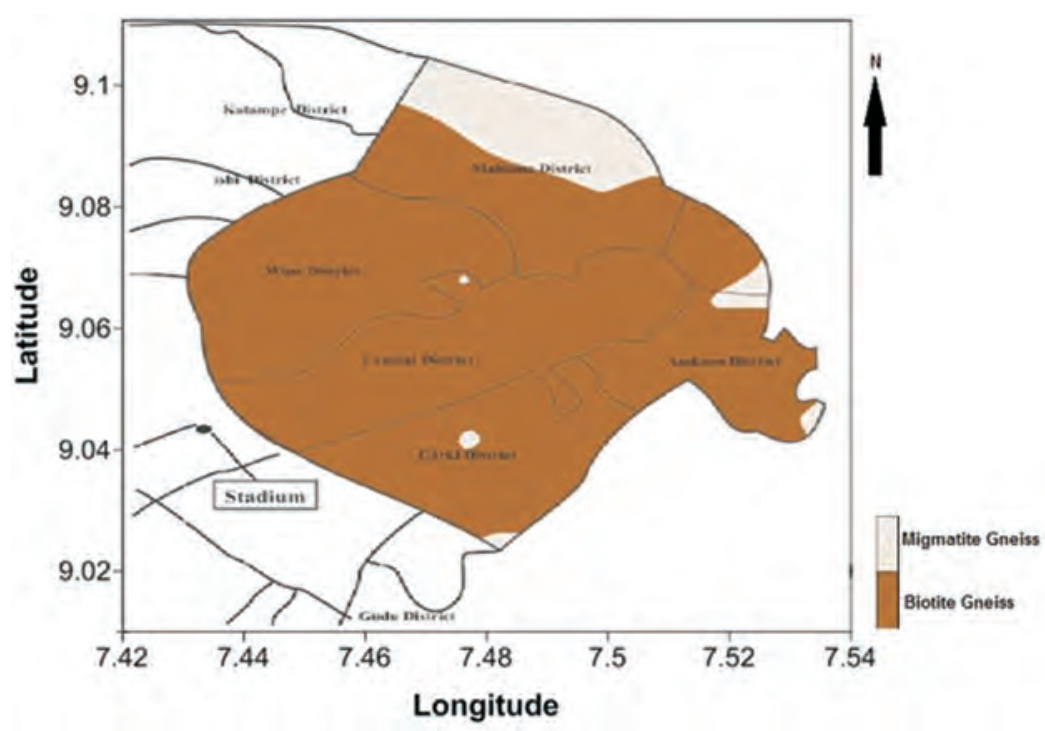

Fig. 2. Map of rocks type in the Abuja metropolis

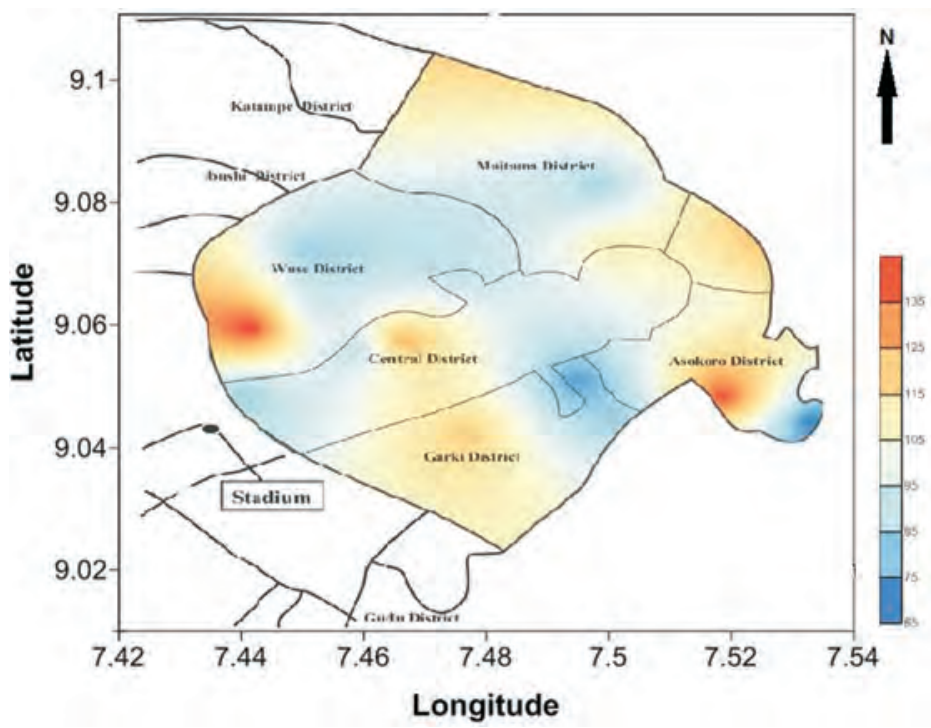

Fig. 3. Magnetic susceptibility distribution of the rocks in the Abuja metropolis

Three dimensional distributions of surface magnetic susceptibility with their depth are presented in Figures 4-7.

In Figure 4 four major areas with enhanced magnetic susceptibility of topsoil were delineated (light blue). These areas are mostly influenced by high vehicle and commercial activities (Adyin \& Akyol 2015). The magnetic susceptibility of topsoil within these regions ranged from $400.0-600.0 \times 10^{-5}$ and, according to Gautam et al. (2004), is considered highly magnetic.

Figure 5 shows the magnetic susceptibility distribution at a depth of $10.0 \mathrm{~cm}$. Highly magnetic soils with a magnetic susceptibility ranging from 400.0 $600.0 \times 10^{-5}$, are still observed though with a reduced surface area when compared with Figure 4.

At a depth of $20.0 \mathrm{~cm}$ (Fig. 6), only two main areas are delineated with high magnetic susceptibility values above $400.0 \times 10^{-5}$. These areas are smaller compared to Figs 4 and 5.

At $30.0 \mathrm{~cm}$ depth (Fig. 7), an anomalous enhanced magnetic susceptibility, with a susceptibility value of about $500.0 \times 10^{-5}$ not observed in the previous maps, may indicate the presence of highly magnetic material or near-surface magnetic rock (indicated by a red arrow). 


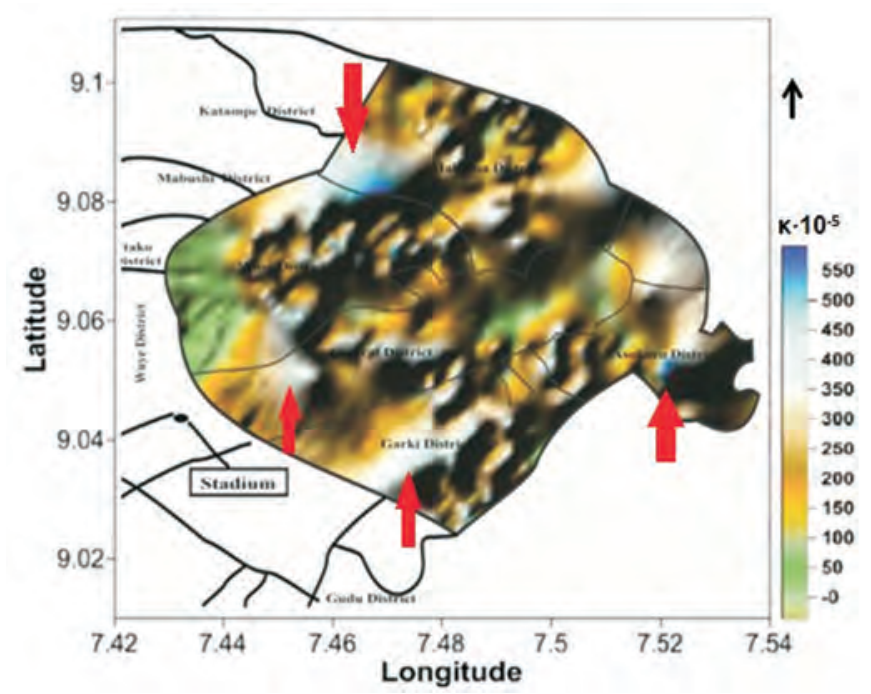

Fig. 4. 3-D surface map of Abuja showing magnetic susceptibility distribution at the surface

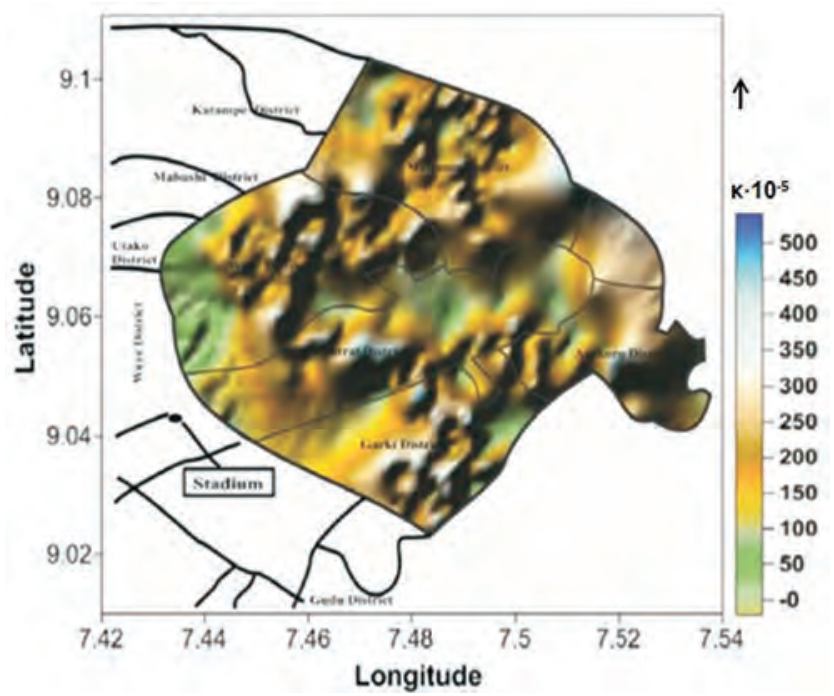

Fig. 5. 3-D surface map of Abuja showing magnetic susceptibility distribution at the depth of $10.0 \mathrm{~cm}$

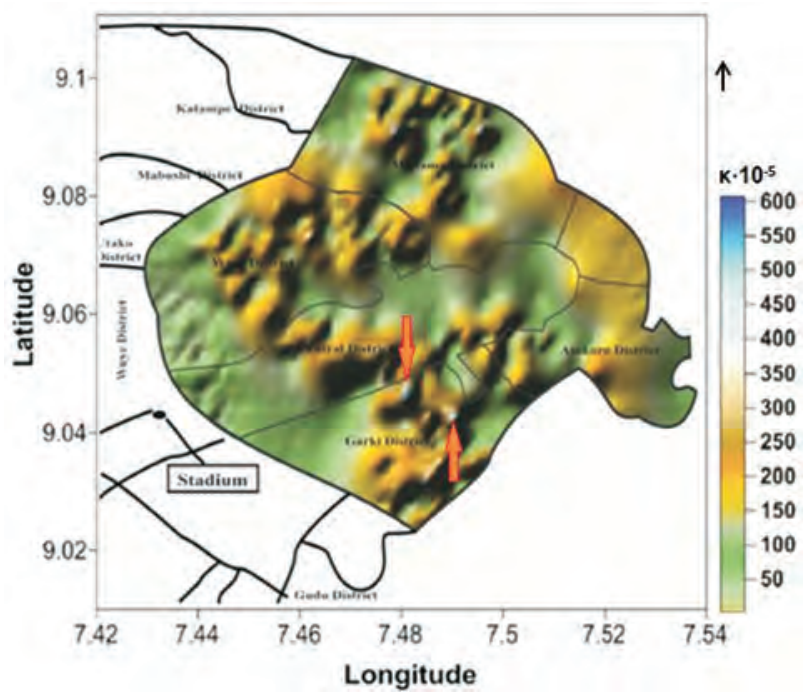

Fig. 6. 3-D surface map of Abuja showing magnetic susceptibility distribution at the depth of $20.0 \mathrm{~cm}$ 


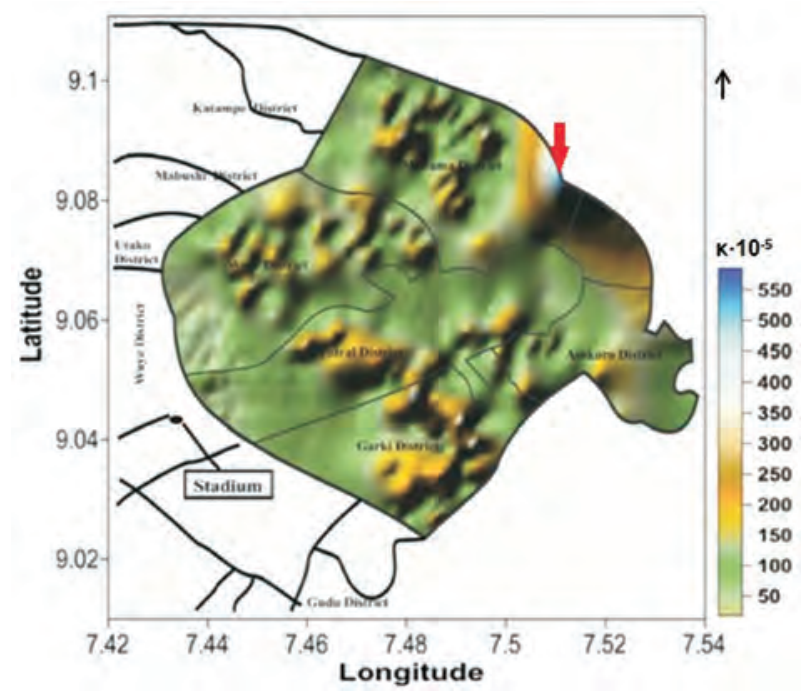

Fig. 7. 3-D surface map of Abuja showing magnetic susceptibility distribution at the depth of $30.0 \mathrm{~cm}$

The decreasing tendency of magnetic susceptibility towards the deeper horizons means that the magnetic particles were accumulated in the topsoil mostly as a result of anthropogenic dust fall, which is mostly common in the vicinity of public roads, and commercial areas.

The high magnetic susceptibility of topsoil, exceeding $400.0 \times 10^{-5}$, is attributed to anthropogenic inputs of magnetic minerals. The anthropogenic magnetic particles may likely come from vehicle emissions (vehicular exhaust, abrasion of tyres and brake linings), commercial activities and waste products.

In Figures 6 and 7, the enhanced magnetic susceptibility values were observed up to $20.0 \mathrm{~cm}$ below the surface, and even up to $30.0 \mathrm{~cm}$ in other areas of the city. The maximum magnetic susceptibility value $600.0 \times 10^{-5}$ ) was observed within the layer $0.0-20.0 \mathrm{~cm}$ below the surface. In this subsurface, the majority of anthropogenic contaminants include technogenic ferromagnetic particles and are related with heavy metals deposited over time (Charzyński et al. eds. 2013).

\section{DISCUSSION AND CONCLUSIONS}

On the 3-D contour maps, the high magnetic susceptibility (ca. $400.0-600.0 \times 10^{-5}$ ) of topsoil is clearly observed in the Abuja metropolis. The high magnetic susceptibility enhancement occurred mostly at the boundaries of the various districts and in this case, is attributed to the fact that the boundaries are made by a major road network linking both districts and residential area together. In the northern part of the Central district and eastern part of the Wuse district, low magnetic susceptibilities are observed. The low susceptibility observed in the Central district is mainly due to the fact that the 3-Arm division (where the presidential lodge is located) is a highly restricted area for commercial and traffic related activities. In the Wuse district, low magnetic susceptibility values are attributed to the terrain of the area which is sloppy and hence most of the magnetic grain deposition is easily transported to a nearby river.

At the subsurface, it is clearly observed that magnetic susceptibility decreases with depth, although some places still indicate high values. Finally, the decreases in magnetic susceptibility with depth is due to the fact that magnetic pollutants have less penetrating abilities and also most of them are easily transported from the surface and deposited either in the river, lakes etc.

At the depth of $30.0 \mathrm{~cm}$, maximum magnetic susceptibility observed is between $250.0-300.0 \times 10^{-5}$. The maximum values occurred in small areas when compared to the whole map. Generally, the map indicates lower magnetic susceptibility of about $(50.0-150.0) \times 10^{-5}$.

From the results, magnetic susceptibility spatial distributions with depth can be a useful tool in delineating areas where the enhanced magnetic susceptibility is a result of anthropogenic pollutants or has a lithogenic origin. It is possible to 
indicate horizons in the soil profile with a high contribution of magnetic materials and in this way, investigate which characteristic type of soil profile it is.

The authors wish to thank the Department of Physics at the Ahmadu Bello University, Zaria, Nigeria for giving us the platform on which this research was sustained, the Centre for Atmospheric Research, Anyigba, and the National Space Research and Development Agency, Abuja for their supports. The authors would also like to thank the anonymous reviewers for their suggestions.

\section{REFERENCES}

Adyin A. \& Akyol E., 2015. Observing urban soil pollution using magnetic susceptibility. International Journal of Environmental Research, 9, 1, 295-302.

Chaparro M.A.E., Gogorza C.S.G., Chaparro M.A.E., Irurzun M.A. \& Sinito A.M., 2006. Review of magnetism and heavy metal pollution studies of various environments in Argentina. Earth Planets Space, 58, 10, 1411-1422.

Dearing J.A., 1999. Environmental Magnetic Susceptibility: Using the Bartington MS2 System. Chi Publishing, Kenilworth, U.K.

Gautam P., Blaha U., Appel E. \& Neupane G., 2004. Environmental magnetic approach towards the quantification of pollution in Kathmandu urban area, Nepal. Physics and Chemistry of the Earth, parts A/B/C 29, 973-984.

Georgeaud V.M., Rochette P., Ambrosi J.P., Vandamme D. \& Williamson D., 1997. Relationship between heavy metals and magnetic properties in a large polluted catchment: The Etang de Berre (south of France). Physics and Chemistry of the Earth, 22, 1-2, 211-214.
Hunt A., Jones J. \& Oldfield F., 1984. Magnetic Measurements and Heavy Metals in Atmospheric Particulates of Anthropogenic Origin. Science of the Total Environment, $33,129-139$.

Kim W., Doh S. J., Park Y. H. \& Yun S. T. 2007. Two-year Magnetc Monitoring in Conjunction with Geochemical and Electron Microscopic Data of Roadside Dust in Seoul, Korea. Atmospheric Environment, 41, 7627-7641.

Knab M., Appel E. \& Hoffmann V., 2001. Separation of the anthropogenic portion of heavy metal contents along a highway by means of magnetic susceptibility and fuzzy c-means cluster analysis. European Journal of Environmental Engineering and Geophysics, 6, 125-140.

Kogbe C.A., 1976. The Cretaceous and Paleogene sediments of southern Nigeria. [in:] Kogbe C.A. (ed.), Geology of Nigeria, Elizabethan Publishing Company, Lagos, 325-334.

Malomo S., Olorunmiwo M.A. \& Ogunsanwo O., 1983. Engineering geology mapping in terrains of tropical weathering: an example of Abuja, Nigeria. Engineering Geology, 19, 133-148.

Petrovský E. \& Ellwood B.B., 1999. Magnetic Monitoring of Pollution of Air, Land and Waters. [in:] Maher B.A. \& Thompson R. (eds.), Quaternary Climates, Environments and Magnetism, Cambridge University Press, Cambridge, 279-322.

Charzyński P., Hulisz P. \& Bednarek R. (eds.), 2013. Technogenic soils of Poland. Polish Soceity of Soil Science, Toruń.

Spiteri C., Kalinski V., Rösler W., Hoffmann V. \& Appel E., 2005. Magnetic screening of a pollution hotspot in the Lausitz area, eastern Germany: correlation analysis between magnetic proxies and heavy metal contamination in soils. Environmental Geology, 49, 1, 1-9.

Thompson R. \& Oldfield F., 1986. Environmental Magnetism. George Allen and Unwin, London.

Zhang C., Huang B., Li Z. \& Liu H., 2006. magnetic properties of highroad-side pine tree leaves in Beijing and their environmental significance. Chinese Science Bulletin, 51, 24, 3041-3052. 